\title{
Structured Quiz for Teaching of CVM Stages to the Undergraduate Orthodontic Students
}

\author{
Dr Muhammad Azeem,' Dr Arfan Ul Haq,2 Dr Zubair Hassan Awaisi,3 Dr Ambreen Afzal Ehsan4 \\ 'Assistant Professor Orthodontics, Dental Section-Faisalabad Medical University/Punjab Medical College, \\ 2Professor of Orthodontics, de'Montmorency College of Dentistry, \\ 3Associate Professor Orthodontics, Nishter Institute of Dentistry, \\ 4Professor of Orthodontics, Altamash Institute of Dental Medicine, Pakistan \\ Correspondence: Dr Muhammad Azeem; Email: dental.concepts@hotmail.com
}

\section{ABSTRACT}

Introduction: There are several methods of teaching out of which didactic lectures and student centered lecturesa re commonly practiced all over the world in medical and dental schools. The aim of the study was to find out the impact of introducing structured quiz as a method for teaching of cervical vertebral maturation (CVM) stages to the undergraduate orthodontic students.

Materials \& Method: Current study was conducted on 30 undergraduate orthodontic students of final year. Duration of Study was 2018-19. Initial MCQs test was followed by the lecture and hands-on on quiz pattern and this was followed by the MCQs final-tests. The scores were calculated and presented in form of mean. Student paired t test was applied to compare the initialtest quiz scores with final-test quiz scores.

Result: Results showed significant differences between initial-test and final-test which showed a significant improvement.

Conclusion: The introduction of structured quiz as a method for teaching of cervical vertebral maturation (CVM) stages resulted in significant improvement in the knowledge of undergraduate orthodontic students.

Keywords: Cervical Vertebra Maturation(CVM) Orthodontics, Quiz.

\section{INTRODUCTION}

There are two main methods of orthodontic or any undergraduate dental teaching.' The traditional method is to go for didactic lectures; this method is considered to be least interactive and teachercentric. ${ }^{2}$ The other latest method is to go for studentcentric teaching with active involvement of students while sessions. ${ }^{3}$

The traditional method which consists of didactic lectures is found to be less interactive; however, it can be modified by inclusion of certain interactive tools. The on such tool is to include structured quiz in lectures to convert the teacher-centric teaching sessions into student-centric teaching sessions. ${ }^{46}$ It has been found that quizzing is as an effective method of teaching to small group of students.?

Cervical vertebral maturation is an important orthodontic topic for teaching to undergraduate dental students. There are several methods of analyzing cervical vertebral maturation. ${ }^{8-10}$ it is usually taught to undergraduate students by lecture sessions, which make its comprehension difficult at the level of undergraduate dental students.

Following this rationale, the aim of present research was to find out the impact of introducing structured quiz as a method for teaching of cervical vertebral maturation stages to the undergraduate orthodontic students. The introduction of structured quiz as a method for teaching of cervical vertebral maturation stages to the undergraduate orthodontic students can make its comprehension easy.

\section{MATERIALS AND METHOD}

This Cross-sectional study was conducted on 30 undergraduate orthodontic students of final year at Dental Section-FMU/PMC, Faisalabad. Duration of study was 2018-2019.

Initial MCQs pre-test was followed by the lecture and hands-on on quiz pattern and this was followed by 
the MCQs post-tests. The scores were calculated and presented in form of mean. Student paired t test was applied to compare the pre-test quiz scores with posttest quiz scores.

The quiz consisted of following stages of cervical vertebral maturation"1 (Table 1):

Table 1: CVM stages

\begin{tabular}{|c|l|}
\hline No. & Description \\
\hline Stage 1 & $\begin{array}{l}\text { Lower borders of C2-C4 are flat. Bodies of C3-C4 } \\
\text { are trapezoidal }\end{array}$ \\
\hline Stage 2 & $\begin{array}{l}\text { Lower border of C2 is concave. Bodies of C3-C4 } \\
\text { are trapezoidal }\end{array}$ \\
\hline Stage 3 & $\begin{array}{l}\text { Lower borders of C2-C3 are concave. Bodies of } \\
\text { C3-C4 are trapezoidal or rectangular horizontal }\end{array}$ \\
\hline Stage 4 & $\begin{array}{l}\text { Lower borders of C2-C4 are concave. Bodies of } \\
\text { C3-C4 are rectangular horizontal }\end{array}$ \\
\hline Stage 5 & $\begin{array}{l}\text { Lower borders of C2-C4 are concave. Body of C3 } \\
\text { or C4 is square }\end{array}$ \\
\hline Stage 6 & $\begin{array}{l}\text { Lower borders of C2-C4 are concave. Body of C3 } \\
\text { or C4 is vertical rectangular }\end{array}$ \\
\hline
\end{tabular}

The scores were calculated and presented in form of mean. Student paired t test was applied to compare the initial-test quiz scores with final-test quiz scores.

\section{RESULT}

Results showed significant differences between initial-test and final-test which showed a significant improvement. (Table 2).

Table 2: Comparison of initial-test scores versus final-test scores ( $n=30$ BDS students)

\begin{tabular}{|c|c|c|}
\hline $\begin{array}{c}\text { Initial-Test } \\
\text { (Mean } \pm \text { SD) }\end{array}$ & $\begin{array}{c}\text { Final-Test } \\
\text { (Mean } \pm \text { SD) }\end{array}$ & P \\
\hline $17 \pm 13 / 100$ & $76 \pm 10 / 100$ & 0.002 \\
\hline
\end{tabular}

\section{DISCUSSION}

The aim of present research was to find out the impact of introducing structured quiz as a method for teaching of cervical vertebral maturation stages to the undergraduate orthodontic students. Modification of didactic lectures by structured quizzing is an innovative way of teaching. ${ }^{4}$ This modified way of teaching can improve students' knowledge of cervical vertebral maturation stages. ${ }^{6}$ This modified way of teaching can also result in improvement of teaching skills. ${ }^{5}$
This cross-sectional study was conducted on 30 undergraduate orthodontic students. Initial MCQs pre-test was followed by the 2 hours lecture and hands-on on quiz pattern and this was followed by the MCQs post-tests. The scores were calculated and presented in form of mean.

The topic of cervical vertebral maturation stages was chosen keeping in mind the importance of it as per BDS curriculum as well as its clinical applicability in orthodontic setups. There are several methods of CVM staging, ${ }^{12-17}$ in the present study CVM stages were taught according to the method of Baccetti et al. ${ }^{11}$

Results of the present study showed significant differences between initial-test and final-test which showed a significant improvement. Mean final-test scores increased significantly as compared to initialtest scores. Thus it was found that introduction of structured quiz as a method for teaching of cervical vertebral maturation-CVM stages resulted in significant improvement in the knowledge of undergraduate orthodontic students. Findings of the current study are in line with the findings of Khan et al., who showed that undergraduate BDS students perceived method of quizzing more knowledge full and interactive. ${ }^{6}$ Findings of the current study are also in line with the findings of Azeem et al., who showed that undergraduate BDS students perceived method of quizzing more friendly and interactive. ${ }^{18}$

There are several limitations of this study, however, within the limitations of current study it was concluded that introduction of structured quiz as a method for teaching of cervical vertebral maturation-CVM stages resulted in significant improvement in the knowledge of undergraduate orthodontic students.

\section{CONCLUSION}

The introduction of structured quiz as a method for teaching of cervical vertebral maturation (CVM) stages resulted in significant improvement in the knowledge of undergraduate orthodontic students.

\section{OJN}




\section{REFERENCES}

1. Wilkinson DM, Smallidge D, Boyd LD, Giblin L. Students' Perceptions of Teaching Methods That Bridge Theory to Practice in Dental Hygiene Education. American Dental Hygienists Association. 2015 Oct 1;89(5):330-7.

2. Saleh AM, Al-Tawil NG, Al-Hadithi TS. Didactic lectures and interactive sessions in small groups: A comparative study among undergraduate students in Hawler College of medicine. Health Education Research. 2016:1427.

3. Johnson GM, Halket CA, Ferguson GP, Perry J. Using Standardized Patients to Teach Complete Denture Procedures in Second Year of Dental School. Journal of dental education. 2017 Mar 1;81 (3):340-6.

4. Resende RG, Abreu CP, Manzi FR, Greco AC. Evaluation of the Use of Educational Application for Teaching Purposes in Dental Radiology. Oral surgery, oral medicine, oral pathology and oral radiology. $2018 \mathrm{Sep} 1 ; 126(3):$ :e 164-5.

5. Leong C, Louizos C, Currie C, Glassford L, Davies NM, Brothwell D, Renaud R. Student perspectives of an online module for teaching physical assessment skills for dentistry, dental hygiene, and pharmacy students. Journal of interprofessional care. 2015 Jul 4;29(4):383-5.

6. Khan S, Maheshwari S, Ghani S, Hakim S, Gaur A. Quizzing as an innovative Teaching-Learning technique for undergraduate dental students. Indian Journal of Orthodontics and Dentofacial Research. 2017 Oct;3(4):235-7.

7. Lone M, Vagg T, Theocharopoulos A, Cryan JF, Mckenna JP, Downer EJ, Toulouse A. Development and Assessment of a Three Dimensiona Tooth Morphology Quiz for Dental Students. Anatomical sciences education. 2018 Oct 30.

8. Perinetti G, Contardo L, Castaldo A, MCNamara Jr JA, Franchi L. Diagnostic reliability of the cervical vertebral maturation method and standing height in the identification of the mandibular growth spurt. The Angle Orthodontist. 2015 Nov 24;86(4):599-609.

9. Cunha AC, Cevidanes LH, Sant'Anna EF, Guedes FR, Luiz RR, McNamara JA, Franchi L, Ruellas AC. Staging hand-wrist and cervica vertebrae images: a comparison of reproducibility. Dentomaxillofacial Radiology. 2018 Mar 10;47(xxxx):20170301.

10. Franchi L, Nieri M, MCNamara JA. Diagnostic reliability of the objective cervical vertebral maturation method for the mandibular growth peak. European Journal of Orthodontics. 2018 Jun 19

11. MCNamara Jr JA, Franchi L. The cervical vertebral maturation method: A user's guide. The Angle Orthodontist. 2018 Jan 16;88(2):133-43.

12. Baccetti T, Franchi L, McNamara Jr JA. The cervical vertebral maturation (CVM) method for the assessment of optimal treatment timing in dentofacial orthopedics. InSeminars in Orthodontics 2005 Sep 1 (Vol. 11, No. 3, pp. 119-129). WB Saunders.

13. Baccetti T, Franchi L, McNamara Jr JA. An improved version of the cervical vertebral maturation (CVM) method for the assessment of mandibular growth. The Angle Orthodontist. 2002 Aug;72(4):316-23.

14. Özer T, Kama JD, Özer SY. A practical method for determining pubertal growth spurt. American Journal of Orthodontics and Dentofacia Orthopedics. 2006 Aug 1;130(2):131-e1.

15. Gray S, Bennani H, Kieser JA, Farella M. Morphometric analysis of cervical vertebrae in relation to mandibular growth. American Journal of Orthodontics and Dentofacial Orthopedics. 2016 Jan 1;149(1):92-8.

16. Nemati S, AZIMI F, Rouhi M, Tafakhori Z. The Relationship between Dental Maturity based on Demirjian's Method and Cervical Vertebrae Maturation Stages in Guilan patients.

17. Perinetti G, Caprioglio A, Contardo L. Visual assessment of the cervical vertebral maturation stages: A study of diagnostic accuracy and repeatability. The Angle Orthodontist. 2014 Mar 25;84(6):951-6.

18. Azeem M, Ali S, Shaukat A, UI Haq A. Effectiveness of Incorporating MCQ in Orthodontic Lectures on Short Term Knowledge Retention of BDS Students. Pak J Med Health Sci. 2018 Jan 1;12(1):206-8. 